\title{
Reconstruction of A Deformed, Partially Edentulous Ridge with A Free Gingival Onlay Graft- A Case Report
}

\author{
Dr. Manthan H. Desai ${ }^{1}$, Dr. Veena A. Patil ${ }^{2}$,Dr. Jignesh R. Patel ${ }^{3}$ \\ ${ }^{I}$ Former Postgraduate Student, Department Of Periodontics, HKE Society's S.N. Institute Of Dental Sciences \\ And Research, Kalaburagi, Karnataka, India. 585105. \\ ${ }^{2}$ Professor and Head, Department Of Periodontics, HKE Society's S.N. Institute Of Dental Sciences And \\ Research, Kalaburagi, Karnataka, India. 585105. \\ ${ }^{3}$ Postgraduate Student,Department Of Periodontics, HKE Society's S.N. Institute Of Dental Sciences And \\ Research, Kalaburagi, Karnataka, India. 585105.
}

Abstract: Soft tissue augmentation with autogenous grafts is widely used in various disciplines of dentistry. Indicated in partially and fully edentulous patients to augment areas with reduced width of keratinized gingiva, as well as to increase soft tissue volume. The following case report describes an unusual presentation of preprosthetic surgery, where ridge reconstruction was done using a free gingival auto graft.

Keywords: Ridge reconstruction, vestibuloplasty, free gingival graft, soft tissue augmentation, pre-prosthetic surgery.

\section{Case Report}

A 26 year male patient was referred to the clinic for pre prosthetic surgery. On examination, teeth 2123 [FDI notation] were missing. A swelling of size $3 \times 2 \mathrm{~cm}$ approximately was seen obliterating the vestibule in the same region [Fig-1].

[Fig-1]: Pre-operative view

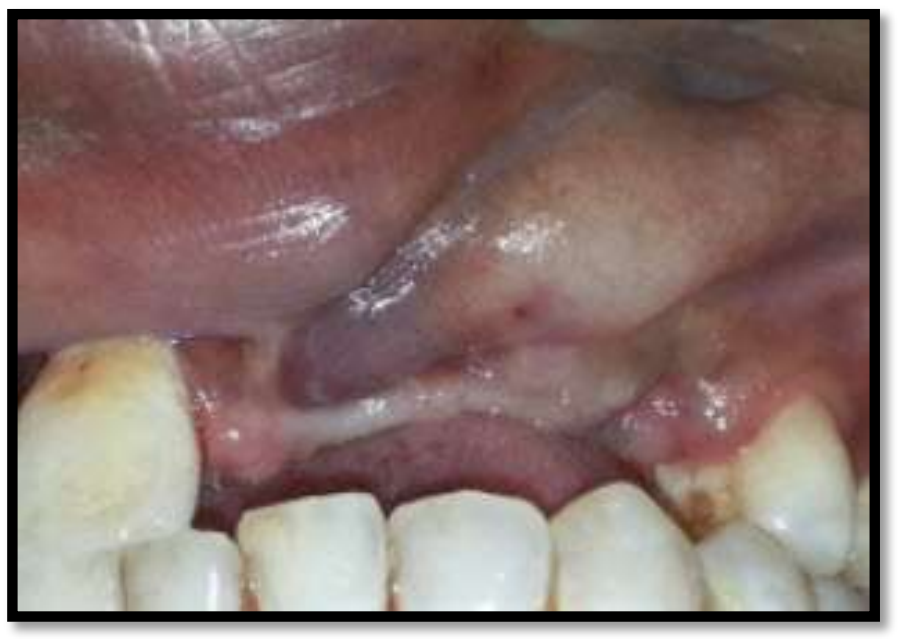

The lesion was mildly tender and firm on palpation. Patient had a history of trauma 6 months ago, during which he lost his upper anterior teeth and had a laceration on the lip. Improper suturing technique by the primary health aid provider resulted in the diminished depth of the vestibule. The patient also noticed a mass developing gradually in the same region. Aspiration biopsy was performed to rule out to rule out any vascular pathology. Radiographic examination showed normal bone morphology. A pre-prosthetic surgery involving the excision of the lesion followed by ridge reconstruction was planned. Treatment plan was elaborated to the patient, and a written informed consent was acquired.The surgical procedure is as follows: local anesthesia was administered, a horizontal vestibular incision was given below the lesion and the whole lesion was excised [Fig2]. 
[Fig-2]: Excision of the lesion

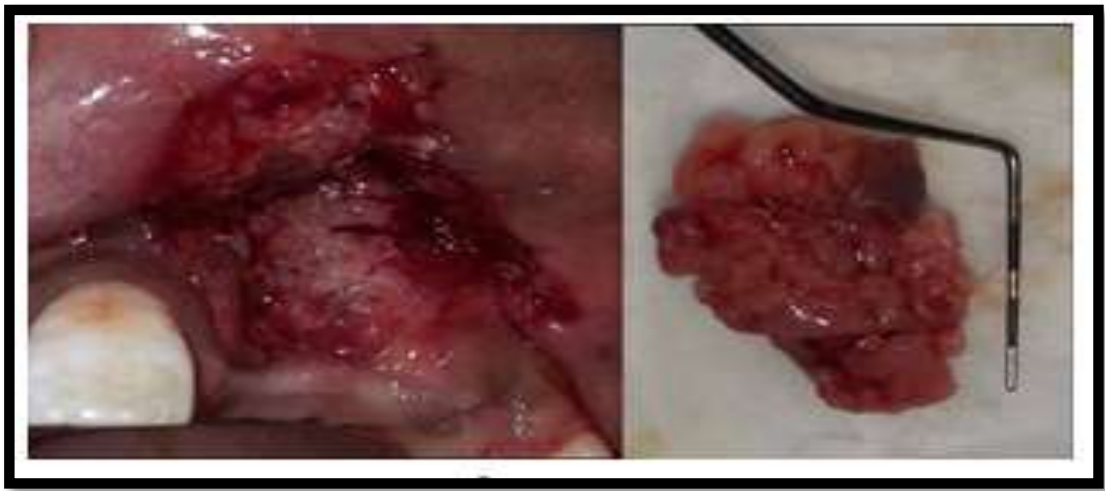

The resulting defect in the vestibule was closed using 3-0 chromic gut sutures. A free gingival graft was harvested from the left palate to perform the ridge reconstruction. This onlay graft was sutured using 4-0 proline on the recipient site. Palatal hemostasis was obtained using 3-0 silk sutures. At the surgical site, a periodontal dressing was placed [Fig-3].

[Fig-3]: Sutures

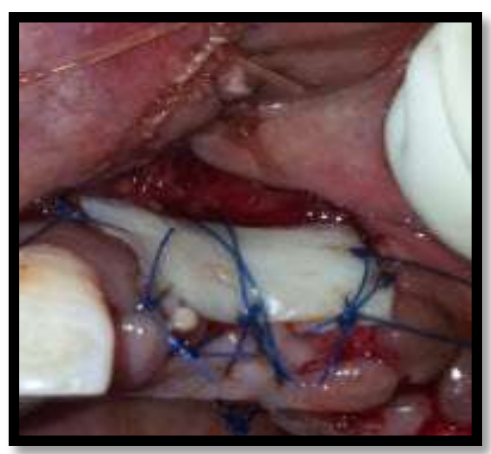

The patient was prescribed antibiotics and analgesics. Excised lesion was sent for histopathology. Uneventful healing was noticed during a post-operative visit.Histopathology revealed the presence of a fibrocellular connective stroma with varying thickness of epithelium. Inflammatory cells and granulation tissue. A follow up after 9 weeks show a reconstructed ridge with adequate vestibular depth [Fig-4].

[Fig-4]: Post-operative view (9 weeks)

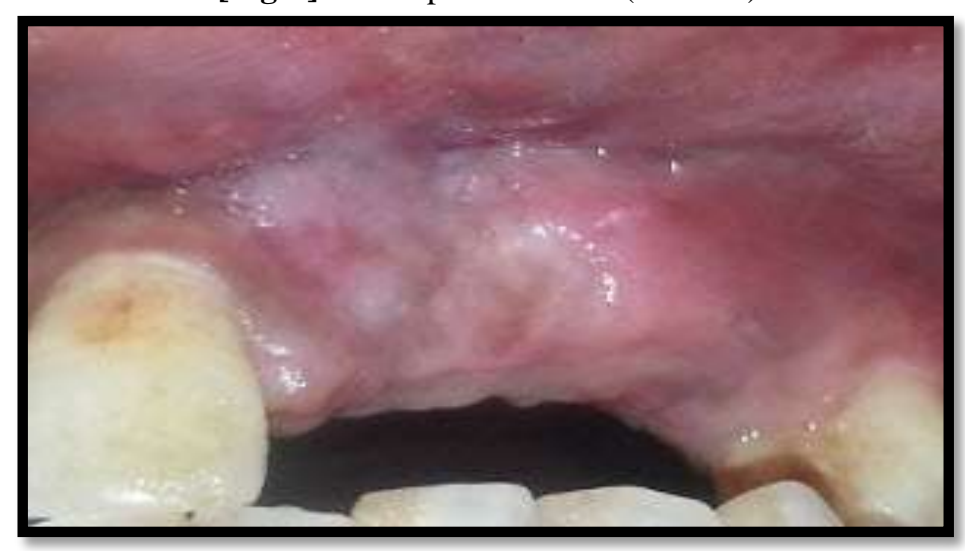

\section{Discussion}

The edentulous ridge with sufficient amount of bone, keratinized tissue and vestibular depth are amongst important requisites for successful prosthetic rehabilitation. A variety of techniques have been proposed to augment bone volume, namely- guided bone regeneration, block grafts, distraction osteogenesis 
etc $^{[1]}$ Management of soft tissues is equally important in compromised cases. The soft tissue status may be worsened by scar tissue development, deficiency of vestibular depth or insufficiency of keratinized gingiva. Various autogenous soft tissue grafting procedures have been proposed to correct localized ridge defects and as pre-prosthetic site development, namely-free gingival graft, connective tissue graft, roll technique etc ${ }^{[2]}$.

Improper habits or trauma leads to imbalance in the orofacial musculature, dentofacial abnormalities, Variations in the bone development etc. Fibroma is a benign, tumor of connective tissue origin. The most common etiology of fibroma is trauma or local irritation. Microscopically, it resembles inflammatory hyperplasia which is self-limiting and resolves on removal of irritating stimulus. A certain amount of keratinized tissue has been considered necessary for maintaining periodontal health ${ }^{[3,4]}$.It was also concluded that for the maintenance of gingival health $2 \mathrm{~mm}$ of keratinized gingiva is adequate ${ }^{[5]}$.Since an adequate amount of keratinized tissue is yet to be decided, the resolution to increase the width of keratinized gingiva still depends upon the preference of clinician. Historically, the methods to augment keratinized tissue included-1) an apically positioned flap (APF), 2) an APF in conjunction with autogenous tissue and, 3) an APF in conjunction with allogenic tissue ${ }^{[6-8]}$. Autogenous soft tissue grafting procedures have also been proposed to surgically correct localized alveolar deficiencies, as a preparation and development of the site during pre-prosthetic surgeries, and as ridge preservation procedures ${ }^{[9-11]}$.

As for the augmentation of keratinized tissue, traditionally, the free gingival graft and the sub epithelial connective tissue graft have been described to increase soft tissue volume. Disadvantages of using autogenous tissue are mainly due to the harvesting procedure, which leads to a prolonged healing time at the donor site and therefore to an increased patient's morbidity ${ }^{[12]}$. In order to overcome these issues with autogenous tissue, alternatives techniques and materials of allogenic origin have been developed - acellular dermal matrix graft (ADMG; Alloderm ${ }^{\mathrm{TM}}$, Life Cell Corporation, The Woodlands, TX), human fibroblastderived dermal substitute (HF-DDS, Dermagraft, Advanced Tissue Sciences, Inc., LaJolla, CA, USA), and ahuman skin equivalent (BCT, Apligraf, Organogenesis, Canton, MA, USA).

\section{Conclusion}

Pre prosthetic surgeries are an integral part of treatment planning in prosthetic rehabilitation. The above described surgical approach provided satisfactory results and also aided in improving the morphology and aesthetics of the alveolar ridge.

\section{References}

[1]. Chiapasco M, Casentini P, Zaniboni M. Bone augmentation procedures in implant dentistry. Int J Oral MaxillofacImplants.2009;24(SUPPL):237-59.

[2]. Evian Cl, al-Maseeh, Symeonides E. Soft tissue augmentation for implant dentistry. CompendContinEduc Dent. 2003;24(3):195-8, 200-2, 204-6; quiz 208.

[3]. Nabers JM. Free gingival grafts. Periodontics. 1966;4(5):243-5.

[4]. Sullivan HC, Atkins JH. The role of free gingival grafts in periodontal therapy. Dent Clin North Am. 1969;13(1):133-48.

[5]. Lang NP, Loe H. The relationship between the width of keratinized gingiva and gingival health. J Periodontol. 1972;43(10):623-7.

[6]. Friedman A. Mucogingival surgery: The apically repositioned flap.

[7]. J Periodontol. 1962;33: 328-40.

[8]. Edel A. Clinical evaluation of free connective tissue grafts used to increase the width of keratinised gingiva. J ClinPeriodontol. 1974;1(4):185-96.

[9]. Yukna RA, Sullivan WM.Evaluation of resultant tissue type following the intraoral transplantation of various lyophilized soft tissues.J Periodontal Res. 1978;13(2):177-84.

[10]. Seibert JS. Reconstruction of deformed, partially edentulous ridges, using full thickness onlay grafts. Part I. Technique and wound healing. CompendContinEduc Dent. 1983;4(5):437-53.

[11]. Studer SP, Lehner C, Bucher A, Scharer P. Soft tissue correction of a single-tooth pontic space: a comparative quantitative volume assessment. J Prosthet Dent. 2000;83(4):402-11.

[12]. Prato GP, Cairo F, Tinti C, Cortellini P, Muzzi L, Mancini EA. Prevention of alveolar ridge deformities and reconstruction of lost anatomy: a review of surgical approaches. Int J Periodontics Restorative Dent. 2004;24(5):434-45.

[13]. FarnoushA.Techniques for the protection and coverage of the donor sites in free soft tissue grafts.JPeriodontol. 1978;49(8):403-5. 